\title{
Cross sectional study of a workforce exposed to hand-arm vibration: with objective tests and the Stockholm workshop scales
}

\author{
Kenneth L McGeoch, W Harper Gilmour
}

\begin{abstract}
Objectives-Medical surveillance of workforces exposed to vibration has been recommended with the Stockholm workshop scales. The aims of this study were (a) to evaluate how the results of the objective tests individually and jointly associated with the final Stockholm workshop staging, (b) how this staging related to the history of exposure to vibration, and (c) how different trades were affected by the hazards from vibrating tools.

Methods-All workers exposed to vibration in a heavy engineering company were examined with a questionnaire and a battery of tests. An assessment of staging by the Stockholm workshop scales was made. Estimates of the daily exposure and lifetime dosage of vibration of the various trades were reached.
\end{abstract}

Results-The average years of tool use was 23.3 years (range $3-47$ years) and the mean lifetime exposure was 11022 (range 101246 125) hours. The individual neurological tests were all strongly associated with the Stockholm neurological staging but the cold provocation test was not associated with the Stockholm vascular staging. Neurological staging was significantly associated with age, years of tool use, and total hours of exposure to vibration, but not with trade or smoking. Vascular staging was significantly associated with age, years of tool use, total hours of exposure to vibration, and trade, but not with smoking. The mean neurological latent period was 19.7 (range 2-40) years and for the vascular component 19.1 (range 2-40) years. These means varied significantly by trade. The overall prevalence of neurological findings of $62 \%$ was greater than the overall prevalence of vascular findings, which was $33 \%$.

Conclusions-(1) The neurological objective tests were found to be of use in neuro-

Accepted 27 August 1999

Table 1 Stockholm workshop scales

\begin{tabular}{|c|c|c|}
\hline Stage & Grade & Description \\
\hline \multicolumn{3}{|c|}{ Vascular component: } \\
\hline 0 & & Exposed to vibration: no symptoms \\
\hline 1 & Mild & Occasional blanching attacks affecting tips of one or more fingers \\
\hline 2 & Moderate & Occasional attacks distal and middle phalanges of one or more fingers \\
\hline 3 & Severe & Frequent attacks affecting all phalanges of most fingers \\
\hline 4 & Very severe & As in 3 with trophic skin changes (tips) \\
\hline \multicolumn{3}{|c|}{ Neurological component: } \\
\hline 0 & & Exposed to vibration: no symptoms \\
\hline 1 & & Intermittent or persistent numbness with or without tingling \\
\hline 2 & & As in 1 with reduced sensory perception \\
\hline 3 & & As in 2 with reduced tactile discrimination and manipulative dexterity \\
\hline
\end{tabular}

logical staging. The cold provocation test was not associated with the vascular staging and therefore was of little value. (2) Years of tool use was the exposure variable most significantly associated with evidence of damage to neurological component while years of tool use and trade were the variables most associated with vascular damage. (3) The prevalence of neurological symptoms $(62 \%)$ was greater than the prevalence of vascular symptoms (33\%). (4) Dressers and welders have shorter latent periods than platers and fitters.

(Occup Environ Med 2000;57:35-42)

Keywords: hand-arm vibration syndrome; neurological objective tests

It has been estimated that in the United Kingdom 4 million people use hazardous vibration equipment and over 1 million are exposed in excess of the Health and Safety Executive's (HSE's) criterion for action $\left(2.8 \mathrm{~m} / \mathrm{s}^{2} \mathrm{~A}(8)\right)$ There may be 170000 people with symptoms of vascular vibration injury including around 20000 cases of advanced disability. ${ }^{1}$

Raynaud's phenomenon of occupational origin became prescribed disease A11 in the United Kingdom under the National Insurance (Industrial Injuries) Act in 1985. This prescription applies only to the vascular problems. During the 1980s the importance of neurological disorders after hand arm exposure to vibration was recognised. In 1986 the Stockholm workshop proposed the name hand-arm vibration syndrome (HAVS) and developed the Stockholm workshop scales. ${ }^{23}$ These scales require the use of the symptomatic history and objective tests to arrive at a diagnosis of HAVS and an accurate staging.

The National Institute for Occupational Safety and Health (NIOSH) ${ }^{4}$ in 1989, the Faculty of Occupational Medicine ${ }^{5}$ in 1993, the $\mathrm{HSE}^{6}$ in 1994, and the Industrial Injuries Advisory Council $1995^{7}$ have all recommended that the Stockholm Workshop Scales (table 1) should replace the Taylor/Pelmear classification. $^{8}$

The $\mathrm{HSE}^{6}$ has recommended that "It is not advisable for a worker to continue exposure (to vibration) if this is likely to result in the disease progressing to either stage 3 vascular or neurological."

This recommendation by the HSE can have serious implications for workers and their companies and makes accurate staging all the more important. 
Letz et $a l^{9}$ after their cross sectional epidemiological survey of a shipyard recommended "further study with objective, quantitative measures of peripheral neurological and vascular function."

We have not been able to trace any epidemiological studies which have used the Stockholm workshop scales and objective tests to show the prevalence of both the neurological and the vascular components of HAVS in a workforce or various trades exposed to vibration.

In a heavy engineering factory various trades were involved with vibratory tools because of the flexible working practices introduced in the 1980s. The extent of this hazard was not known and guidance was not available.

Letz et $a l^{9}$ and $\mathrm{NIOSH}^{4}$ have described the extreme variability between the acceleration measures found on the same tools in different studies and even within studies. This precludes the use of the vibration dose to produce a cumulative acceleration exposure index for individual people. Griffin ${ }^{10}$ has also drawn attention to the problems with the existing standards and weighting frequencies. It is for these reasons that control by medical surveillance has been recommended. ${ }^{4-6}$

In this study the association of the final staging with the individual objective test results was investigated in an attempt to meet the recommendation of Letz et al. It also looked at the association of the vascular and neurological Stockholm staging with years of use of vibratory tools, total hours of exposure to vibration, and other variables including age and trade. The latent periods and prevalances in several trades were investigated.

\section{Methods}

The examinations took place in a dedicated room in the Occupational Health Department at the start of the working day before exposure to vibration. Each examination took between 2 and 2.5 hours. The first 50 examinations were performed by the first author and the rest by two trained nurses with the final staging being agreed with the first author. It took 3 years to complete the examinations. The workers included in the study represented $100 \%$ of the workforce exposed to vibration during the period of the study. There was no recruitment during this time. We consider this to be a cross sectional study despite the time required to complete the examinations.
SUBJECTS

Altogether 180 men were examined and 15 were excluded from the study because of the presence of other medical conditions complicating any examination (carpal tunnel syndrome, prescribed disease A12, two cases, cardiovascular problems seven, primary Raynaud's disease one, finger or forearm injuries four, and diabetes mellitus one) leaving 165 for analysis. These comprised 74 welders, 58 fitters, 17 platers, and 16 dressers.

\section{EXAMINATION}

A full history of vascular and neurological symptoms, latency, and present and past use of vibratory tools was taken. To aid with the differential diagnosis a detailed medical history was recorded. A clinical examination included inspection of the hands, blood pressure, touch sensation, and Adson, Allen, Tinel, and Phalen tests. The objective tests were performed in the following order (a) grip strength, (b) a modified Moberg pickup test, ${ }^{11}$ (c) aesthesiometry as described by Renfrew and modified by Carlson, ${ }^{12-14}(d)$ vibrotactile threshold with an HVLab vibrometer, ${ }^{15}{ }^{16}(e)$ measurement of the thermal neutral zones and thermal pain thresholds with the Sonemedic Thermotest, ${ }^{17}{ }^{18}$ and $(f)$ a controlled cold provocation test $15^{\circ} \mathrm{C}$ for 5 minutes. ${ }^{19}$

The detailed symptomatic history was used to arrive at a diagnosis of HAVS. The results of the clinical examination and the objective tests were used to assess the severity of the damage and thereby a Stockholm workshop staging.

Details of the scoring system used to assess the extent of the abnormalities found with the aesthesiometry, thermal neutral zones, vibrotactile threshold, and controlled cold provocation test are given in table 2 , and was similar to that used in a previous publication ${ }^{20}$ and by Lawson. ${ }^{21}$ The total neurological hand score was reached by adding the aesthesiometry, thermal neutral zones, and vibrotactile threshold scores. A neurological stage 1 had zero or low hand scores, (usually <8) and neurological stage 2 higher hand scores (usually $>8$ ). Borderline scores required a clinical judgement taking into consideration all the known facts. For a neurological stage 3 staging there had to be evidence of a loss of dexterity.

EXPOSURE TO VIBRATION

Welders used pneumatic grinders and pneumatic chipping hammers. All the other exposed workers used only pneumatic grinders although most of the dressers would have previously used caulking hammers.

Table 2 Scoring system for the neurological tests and the cold provocation test

\begin{tabular}{|c|c|c|c|c|}
\hline Test & Score 0 & Score 1 & Score 2 & Score 3 \\
\hline $\begin{array}{l}\text { Aesthesiometry for each finger }(\mathrm{cm}) \\
\text { TNZ for each finger }\left({ }^{\circ} \mathrm{C}\right) \\
\text { VTT threshold }(\mathrm{m} / \mathrm{s})(31.5 \mathrm{~Hz} \text { index } \\
\text { and little finger) } \\
\text { VTT threshold }(\mathrm{m} / \mathrm{s})(125 \mathrm{~Hz} \text { index } \\
\text { and little finger) } \\
\text { CPT for each finger }\end{array}$ & $\begin{array}{l}\leq 6.0 \\
\leq 10 \\
\leq 0.40 \\
\leq 0.60 \\
\text { Rewarming to } 22^{\circ} \mathrm{C} \text { within } \\
5 \text { minutes, and } 30^{\circ} \mathrm{C} \text { by } 10 \\
\text { minutes }\end{array}$ & $\begin{array}{l}6.1-8.0 \\
11-15 \\
0.41-0.60 \\
0.61-1.00 \\
\text { Failing to rewarm to } 22^{\circ} \mathrm{C} \\
\text { by } 5 \text { minutes, but reaching } \\
30^{\circ} \mathrm{C} \text { by } 10 \text { minutes }\end{array}$ & $\begin{array}{l}8.1-12.0 \\
>15 \\
>0.60 \\
>1.00 \\
\text { Failing to reach } 22^{\circ} \mathrm{C} \text { by } 5 \\
\text { minutes and } 30^{\circ} \mathrm{C} \text { by } 10 \\
\text { minutes }\end{array}$ & $\begin{array}{l}>12 \\
>15+\text { abnormal thermal pain }\end{array}$ \\
\hline
\end{tabular}


Table 3 Concordance between vascular and neurological staging

\begin{tabular}{lrrrrr}
\hline \multicolumn{7}{l}{ Vascular stage } \\
\cline { 2 - 6 } & \multicolumn{1}{c}{1} & 2 & 3 & All \\
\hline Neurological stage: & 61 & 1 & 1 & 0 & \\
0 & 41 & 22 & 8 & 0 & 71 \\
1 & 8 & 4 & 16 & 2 & 30 \\
2 & 0 & 0 & 0 & 1 & 1 \\
3 & 110 & 27 & 25 & 3 & 165 \\
All & & & & & \\
\hline
\end{tabular}

Unfortunately, the historical records of exposure to vibration were poor and it was not possible to reach reasonably accurate estimates of the dose. Therefore, before the start of the examinations, a 3 week study took place. The acceleration values of the tools and workers' exposure times were measured. The daily exposure times were estimated at $(a)$ welders and platers 1.5 hours, $(b)$ fitters 2 hours, and (c) dressers 5 hours.

These times include an allowance for overtime and weekend working. The factory had a normal working year of 225 days. The lifetime dose of exposure to vibration in hours was estimated for each worker, by the formula:

average daily exposure time $\times 225 \times$ years worked

STATISTICAL METHODS

Because of small numbers of subjects in neurological stage 3, neurological stages 2 and 3 were combined for the analysis. For the same reason vascular stages 2 and 3 were combined. There were no cases of vascular stage 4 . When comparing subjects in different stages, $\chi^{2}$ tests were used to test for association with categorical variables and one way analysis of variance (ANOVA) was used to compare mean values of continuous variables. For continuous variables with skewed distributions, except for the vibrotactile thresholds, the results of the one way ANOVA were confirmed by a Kruskal-Wallis test. As the Kruskal-Wallis test and the ANOVA gave very similar results only the results of the one way ANOVA are presented. For the vibrotactile thresholds, which are very positively skewed, a log transformation (base 10) was used to produce an approximate normal distribution before carrying out the one way ANOVA. For the controlled cold provocation test, the scores on a $1-8$ scale had a $U$ shaped distribution with $27 \%$ of subjects scor- ing 0 and $42 \%$ scoring 8 . The controlled cold provocation test score was categorised by grouping scores of 1-7 together to facilitate the analysis.

Stepwise ordinal logistic regression ${ }^{21} 22$ was used to determine which combinations of objective tests were most strongly associated with being in neurological stage 1 and neurological stage 2 or 3 , after adjusting for the effects of the other objective tests. Stepwise ordinal logistic regression was also used to determine which exposure history variables were most strongly associated with being in neurological stage 1 and neurological stage 2 or 3, after adjusting for the effects of other variables in history.

\section{Results}

Symptoms were recorded for the right and left hands separately. However, as 158 subjects $(96 \%)$ had both hands at the same neurological stage and 152 subjects (92\%) had both hands at the same vascular stage with only three subjects having hands which differed by two stages (all vascular), data are presented for the right hand only.

Table 3 shows the relation between neurological and vascular stage. One hundred and two subjects $(62 \%)$ had neurological symptoms (stage $\geqslant 1$ ), whereas 55 subjects $(33 \%)$ had vascular symptoms (stage $\geqslant 1), 61$ subjects $(37 \%)$ had neither neurological nor vascular symptoms, whereas 53 subjects $(32 \%)$ had both neurological and vascular symptoms.

The mean age of the subjects was 41.4 (SD 11.3 , range 19-61) years. There were $43 \%$ non-smokers, $22 \%$ ex-smokers, and 35\% current smokers, and 94\% were right handed. They had been exposed to tool use for an average of 23.3 (SD 11.3, range 3 to 47) years and their mean estimated total hours of exposure to tool use was 11022 hours (SD 8707, range 1012-46 125 hours).

\section{STAGE AND OBJECTIVE TESTS}

Neurological stage

Table 4 shows that the neurological staging was significantly associated with grip strength, aesthesiometry, thermal neutral zones, and vibrotactile threshold at both $31.5 \mathrm{~Hz}$ and $125 \mathrm{~Hz}$. Stepwise ordinal logistic regression was carried

Table 4 Association of objective test scores with neurological staging

\begin{tabular}{|c|c|c|c|c|}
\hline \multirow[b]{2}{*}{ Test } & \multicolumn{3}{|l|}{ Neurological stage } & \multirow[b]{2}{*}{$p$ Value } \\
\hline & 0 & 1 & 2 or 3 & \\
\hline $\mathrm{n}$ & 63 & 71 & 31 & \\
\hline Grip (kg, mean (SD)) & $101.3(17.1)$ & $98.4(13.6)$ & $92.6(16.9)$ & 0.04 \\
\hline Aesthesiometry (mean (SD)) & $3.44(3.13)$ & $3.92(2.91)$ & $7.94(1.53)$ & $<0.001$ \\
\hline TNZ (mean (SD)) & $2.06(2.44)$ & $3.00(2.33)$ & $6.23(3.06)$ & $<0.001$ \\
\hline VTT $31.5 \mathrm{~Hz}($ mean (SD)) & $0.59(0.79)$ & $0.92(1.03)$ & $3.95(4.95)$ & \\
\hline Median (quartiles) & $0.34(0.19,0.61)$ & $0.54(0.31,0.96))$ & $2.09(0.78,4.55)$ & $<0.001$ \\
\hline$\leq 0.40 \mathrm{~m} / \mathrm{s}(\%)$ & 59 & 37 & 6 & \\
\hline $0.41-0.60 \mathrm{~m} / \mathrm{s}(\%)$ & 16 & 17 & 13 & $<0.001$ \\
\hline$>0.60 \mathrm{~m} / \mathrm{s}(\%)$ & 25 & 46 & 81 & \\
\hline VTT $125 \mathrm{~Hz}$ (mean (SD)) & $0.99(1.27)$ & $1.36(1.50)$ & $6.64(8.55)$ & \\
\hline Median (quartiles) & $0.58(0.26,1.25)$ & $0.91(0.45,1.60)$ & $3.12(1.49,8.22)$ & $<0.001$ \\
\hline$\leq 0.60 \mathrm{~m} / \mathrm{s}(\%)$ & 54 & 38 & 10 & \\
\hline $0.61-1.00 \mathrm{~m} / \mathrm{s}(\%)$ & 17 & 23 & 6 & $<0.001$ \\
\hline$>1.00 \mathrm{~m} / \mathrm{s}(\%)$ & 29 & 39 & 84 & \\
\hline
\end{tabular}

Abbreviations as for table 2 . 


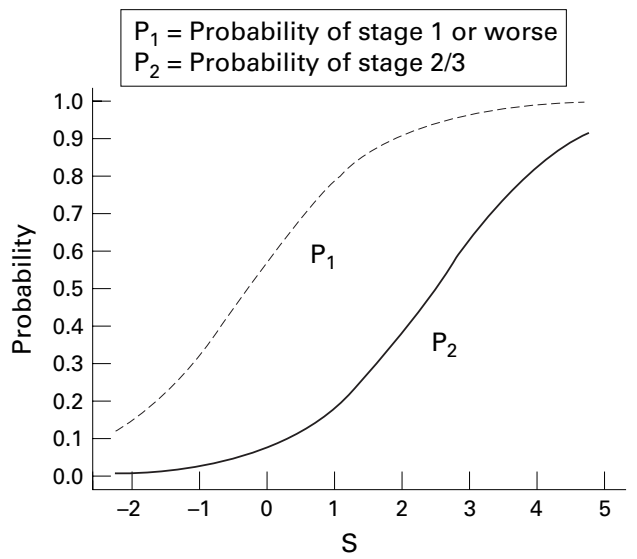

Figure 1 Relation between probability of neurological stage and objective tests, based on ordinal logistic regression.

out to identify the simplest model for predicting the neurological stage based on the objective tests. Only thermal neutral zones $(p<0.001)$ and $\log _{10}$ vibrotactile threshold 31.5 $(\mathrm{p}<0.001)$ were included in the final model as none of the other remaining objective tests were significantly associated with the neurological stage in addition to these two. The final model was:

$$
\begin{gathered}
P_{2}=\begin{array}{l}
\text { Probability that a subject is at } \\
\text { neurological stage } 2 \text { or } 3
\end{array} \\
\quad=\frac{\exp (-2.475+S)}{1+\exp (-2.475+S)}
\end{gathered}
$$

$\mathrm{P}_{1}=$ Probability that a subject is at neurological stage 1 or worse

$$
=\frac{\exp (0.288+\mathrm{S})}{1+\exp (0.288+\mathrm{S})}
$$

$$
\begin{gathered}
P_{0}=\text { Probability that a subject is at } \\
\text { neurological stage } 0=1-P_{1}
\end{gathered}
$$

where $S=0.2863 \times$ thermal neutral zones + $2.067 \times \log _{10}$ (vibrotactile threshold 31.5 ).

This model allows the probability of being at neurological stage 0,1 , or 2 or 3 to be estimated for a worker whose vibrotactile threshold $31.5 \mathrm{~Hz}$ and thermal neutral zones are known.
Figure 1 displays this model graphically. For example, for a subject with a thermal neutral zones score of 0 and a vibrotactile threshold $31.5 \mathrm{~Hz}$ of $0.2, \mathrm{~S}=-1.4448$ and the predicted probabilities of being in neurological stage 0 , neurological stage 1 , or neurological stage 2 or 3 are $0.76,0.22,0.02$ respectively, whereas for a subject with thermal neutral zones score of 8 and a vibrotactile threshold $31.5 \mathrm{~Hz}$ of 2.0 , $\mathrm{S}=2.9126$ and the corresponding predicted probabilities are $0.04,0.35,0.61$.

\section{Vascular stage}

The only objective test specifically designed to detect vascular damage is the cold provocation test. However table 5 shows that the association between the controlled cold provocation test and vascular stage was not significant $\left(\chi^{2}\right.$ test, $\mathrm{p}=0.36$ ). Table 5 also shows that vascular stage is significantly associated with aesthesiometry, thermal neutral zones, and vibrotactile thresholds at both $31.5 \mathrm{~Hz}$ and $125 \mathrm{~Hz}$.

Stepwise ordinal logistic regression was carried out to identify the simplest model for predicting the vascular stage. Only thermal neutral zones $(p=0.023)$ and $\log _{10}$ vibrotactile threshold $125 \mathrm{~Hz}(\mathrm{p}=0.005)$ were included in the final model. The relation between these and the vascular staging was not as strong as for the neurological staging. The vibrotactile threshold $125 \mathrm{~Hz}$ was more strongly associated with the vascular stage than the vibrotactile threshold $31.5 \mathrm{~Hz}$.

STAGE AND EXPOSURE HISTORY

Neurological stage

Table 6 shows the association between neurological stage and several explanatory variables. There is no significant association between stage and trade $(p=0.15)$ or smoking habit $(p=0.27)$. However for age, years of tool use, and total hours of exposure to tool use there was a significant increase in the mean from neurological stage 0 to neurological stage 1 and to neurological stage 2 or $3(\mathrm{p}<0.0001$ in each

\begin{tabular}{|c|c|c|c|c|}
\hline \multirow[b]{2}{*}{ Test } & \multicolumn{3}{|l|}{ Vascular stage } & \multirow[b]{2}{*}{$p$ Value } \\
\hline & 0 & 1 & 2 or 3 & \\
\hline Number & 110 & 27 & 28 & \\
\hline Grip (kg, mean (SD)) & $100.4(16.1)$ & $94.4(12.9)$ & $94.6(16.6)$ & 0.08 \\
\hline Aesthesiometry (mean (SD)) & $3.86(3.13)$ & $5.33(3.40)$ & $6.14(2.90)$ & $<0.001$ \\
\hline TNZ (mean (SD)) & $2.77(2.71)$ & $3.26(2.67)$ & $5.11(3.27)$ & $<0.001$ \\
\hline VTT $(31.5 \mathrm{~Hz}$, mean (SD)) & $0.95(1.44)$ & $2.02(4.38)$ & $2.36(3.48)$ & \\
\hline Median (quartiles) & $0.43(0.25,0.93)$ & $0.67(0.35,1.77))$ & $0.98(0.46,2.65)$ & 0.004 \\
\hline$\leq 0.40(\mathrm{~m} / \mathrm{s}, \%)$ & 47 & 26 & 21 & \\
\hline $0.41-0.60(\mathrm{~m} / \mathrm{s}, \%)$ & 15 & 19 & 14 & 0.04 \\
\hline$>0.60(\mathrm{~m} / \mathrm{s}, \%)$ & 37 & 56 & 64 & \\
\hline VTT $(125 \mathrm{~Hz}$, mean (SD)) & $1.54(3.21)$ & $3.65(7.73)$ & $3.48(3.75)$ & \\
\hline Median (quartiles) & $0.68(0.32,1.46)$ & $1.02(0.46,1.91)$ & $1.68(0.99,5.70)$ & $<0.001$ \\
\hline$\leq 0.60(\mathrm{~m} / \mathrm{s}, \%)$ & 47 & 30 & 14 & \\
\hline $0.61-1.00(\mathrm{~m} / \mathrm{s}, \%)$ & 19 & 19 & 11 & 0.002 \\
\hline$>1.00(\mathrm{~m} / \mathrm{s}, \%)$ & 34 & 52 & 75 & \\
\hline \multicolumn{5}{|l|}{ CPT score: } \\
\hline $0(\%)$ & 25 & 41 & 18 & \\
\hline $1-7(\%)$ & 31 & 30 & 32 & 0.36 \\
\hline $8(\%)$ & 44 & 30 & 50 & \\
\hline
\end{tabular}
case).

Stepwise ordinal logistic regression was used to investigate which of these variables were associated with the neurological stage, after

Table 5 Association of objective test scores with vascular staging

Abbreviations as for table 2 . 
Table 6 Exposure factors associated with neurological stage

\begin{tabular}{|c|c|c|c|c|}
\hline & \multicolumn{3}{|c|}{ Neurological stage } & \multirow[b]{2}{*}{ p Value } \\
\hline & 0 & 1 & 2 or 3 & \\
\hline $\mathrm{n}$ & 63 & 71 & 31 & \\
\hline Age (mean (SD)) & $36.2(11.9)$ & $42.7(10.2)$ & $48.9(6.3)$ & $<0.0001$ \\
\hline Trade (n (\%)): & & & & 0.15 \\
\hline Welder & $31(42)$ & $34(46)$ & $9(12)$ & \\
\hline Fitter & $22(38)$ & $24(41)$ & $12(21)$ & \\
\hline Plater & $7(41)$ & $7(41)$ & $3(18)$ & \\
\hline Dresser & $3(19)$ & $6(38)$ & $7(44)$ & \\
\hline Smoking (n (\%)): & & & & 0.27 \\
\hline Current & $19(33)$ & $25(43)$ & $14(24)$ & \\
\hline Non-smoking & $33(47)$ & $27(39)$ & $10(14)$ & \\
\hline Ex-smoking & $11(30)$ & $19(51)$ & $7(19)$ & \\
\hline Tool use (y, mean (SD)) & $17.2(11.3)$ & $25.1(10.3)$ & $31.5(5.9)$ & $<0.0001$ \\
\hline Exposure (h, mean (SD)) & $7135(5069)$ & $11577(8704)$ & $17644(10330)$ & $<0.0001$ \\
\hline
\end{tabular}

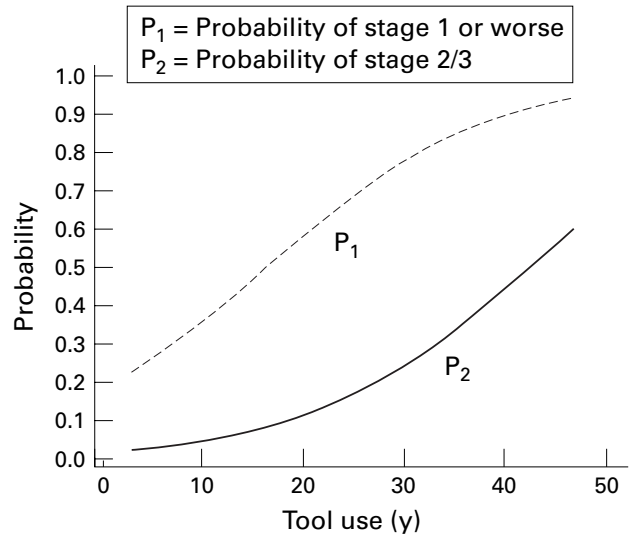

Figure 2 Relation between probability of neurological stage and years of tool use, based on ordinal logistic regression.

adjusting for the effects of all other variables. The most significant factor was the number of years of tool use. After this was entered into the model, none of the other explanatory variables were significant.

The fitted model estimates the probability that a subject is at a particular neurological stage, for a given number of years of tool use, and can be summarised as follows:

$$
\begin{gathered}
P_{2}=\begin{array}{c}
\text { Probability that subject is at } \\
\text { neurological stage } 2 \text { or } 3
\end{array} \\
=\frac{\exp (-3.823+0.0898 \times T)}{1+\exp (-3.823+0.0898 \times T)}
\end{gathered}
$$

$P_{1}=$ Probability that subject is at neurological stage 1 or worse $=\frac{\exp (-1.473+0.0898 \times T)}{1+\exp (-1.473+0.0898 \times T)}$

$\mathrm{P}_{0}=$ Probability that a subject is at
neurological stage $0=1-\mathrm{P}_{1}$ where $\mathrm{T}=$ number of years of tool use.

Figure 2 displays this model graphically. For example, for a subject with 10 years of tool use, the predicted probabilities of being in neurological stage 0 , neurological stage 1 , or neurological stage 2 or 3 are $0.64,0.31,0.05$, respectively based on this model, whereas for a subject with 30 years of tool use the corresponding predicted probabilities are $0.23,0.53,0.24$.

Vascular stage

Table 7 shows the association between vascular stage and the explanatory variables. There is no significant association between stage and smoking habit $(p=0.47)$, but there is a significant association between stage and trade $(p=0.03)$ with dressers, in particular, being more likely to have symptoms. Age, years of tool use, and total hours of exposure to tool use were highly significant $(\mathrm{p}<0.0001)$, as for the neurological staging. Stepwise ordinal logistic regression was used to investigate which of these variables was associated with the vascular stage, after adjusting for the effects of all other variables. Two variables were entered into the model-years of tool use $(p<0.0001)$ and trade $(p=0.005)$. No other variables were significant in addition to these two.

The fitted model estimates the probability that a subject is at a particular vascular stage, for a given number of years of tool use for each trade. The numbers of platers and dressers in the sample is too small to allow probabilities for these categories to be estimated with acceptable precision. The model is summarised for the two largest occupational groups:

For welders:

$\mathrm{P}_{2}=$ Probability that subject is at vascular stage 2 or $3=$ $\exp (-3.865+0.099 \times T)$ $1+\exp (-3.865+0.099 \times T)$

$P_{1}=$ Probability that subject is at vascular stage 1 or worse $=\frac{\exp (-2.742+0.099 \times T)}{1+\exp (-2.742+0.099 \times T)}$

$\mathrm{P}_{0}=$ Probability that subject is at vascular stage $0=1-P_{1}$

For fitters:

$\mathrm{P}_{2}=$ Probability that subject is at vascular stage 2 or $3=$ $\exp (-5.216+0.099 \times T)$ $\overline{1+\exp (-5.216+0.099 \times T)}$

$\mathrm{P}_{1}=$ Probability that subject is at vascular stage 1 or worse

$=\frac{\exp (-4.094+0.099 \times T)}{1+\exp (-4.094+0.099 \times T)}$ 
$P_{0}=$ Probability that subject is at vascular stage $0=1-P_{1}$

where $\mathrm{T}=$ number of years of tool use.

Figure 3 displays this model graphically and table 8 gives examples of the predicted probabilities of developing vascular symptoms based on this model.

For those workers with symptoms, the mean latent period was 19.7 (SD 8.9, range 2 to 40 ) years for neurological symptoms and 19.1 (SD 8.7, range 2 to 40 ) years for vascular symptoms. For those with symptoms, the mean latent period was significantly different between trades for both neurological $(p<0.001)$ and vascular $(p<0.001)$ symptoms. For neurological symptoms, fitters (mean 25.9 years) and platers (mean 22.3 years) had significantly longer latent periods than dressers (mean 17.2 years) or welders (mean 15.4 years). For vascular symptoms, fitters (mean 26.8 years) and platers (mean 21.0 years) had significantly longer latent periods than dressers (mean 15.8 years) or welders (mean 15.3 years).

\section{Discussion}

This study was carried out on a typical heavy engineering company. The use of vibratory tools was in no way exceptional.

As all workers exposed to vibration were included in this study the problem of nonattenders or non-responders did not arise.

The detailed history of the signs and symptoms was essential when making a diagnosis of HAVS and to give a first estimate of a possible Stockholm workshop staging. However it has been shown that staging by questionnaire and staging by questionnaire plus objective tests does not give the same results. $^{23}$ Pelmear et al found that the agreement was $<45 \%{ }^{24}$ They also state categorically "that it was not the intention of the authors of the Stockholm workshop scales to classify workers from the severity of the reported symptoms." As no single test can reliably stage either the vascular or neurological components the use of a battery of tests has been recommended. ${ }^{4-6}$

In this study we arrived at a Stockholm workshop staging by taking into account the history of signs and symptoms, the results of

Table 7 Exposure factors associated with vascular stage

\begin{tabular}{|c|c|c|c|c|}
\hline & \multicolumn{3}{|l|}{ Vascular stage } & \multirow[b]{2}{*}{ p Value } \\
\hline & 0 & 1 & 2 or 3 & \\
\hline $\mathrm{n}$ & 110 & 27 & 28 & \\
\hline Age (mean (SD)) & $39.1(11.9)$ & $45.1(9.3)$ & $46.6(7.4)$ & $<0.0001$ \\
\hline Trade $(\mathrm{n}(\%))$ : & & & & 0.03 \\
\hline Welder & $49(66)$ & $16(22)$ & $9(12)$ & \\
\hline Fitter & $44(76)$ & $5(9)$ & $9(16)$ & \\
\hline Plater & $11(65)$ & $3(18)$ & $3(18)$ & \\
\hline Dresser & $6(38)$ & $3(19)$ & $7(44)$ & \\
\hline Smoking (n (\%)): & & & & 0.47 \\
\hline Current & $34(59)$ & $13(22)$ & $11(19)$ & \\
\hline Non-smoking & $51(73)$ & $8(11)$ & $11(16)$ & \\
\hline Ex-smoking & $25(68)$ & $6(16)$ & $6(16)$ & \\
\hline Tool use (y, mean (SD)) & $20.6(11.6)$ & $27.2(9.8)$ & $30.0(7.3)$ & $<0.0001$ \\
\hline Exposure (h, mean (SD)) & $9171(7495)$ & $12579(9714)$ & $16786(9587)$ & $<0.0001$ \\
\hline
\end{tabular}
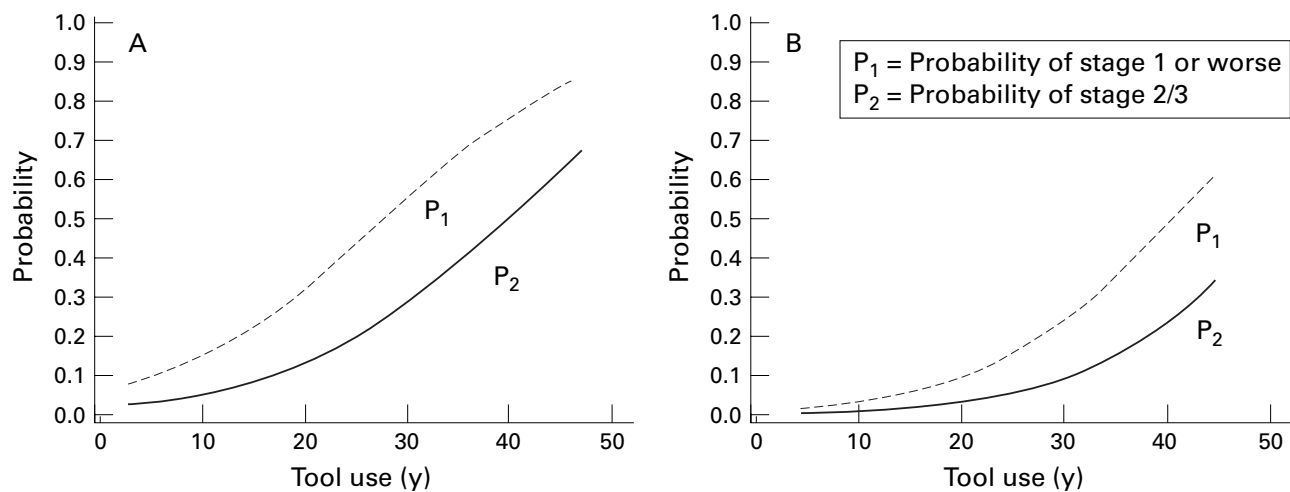

Figure 3 Relation between probability of vascular stage and years of tool use by trade, based on ordinal logistic regression; (A) welders; (B) fitters.

Table 8 Predicted probability of vascular symptoms by trade and years of tool use, based on ordinal logistic regression

\begin{tabular}{|c|c|c|c|c|c|c|}
\hline \multirow[b]{2}{*}{ Tool use $(y)$} & \multicolumn{3}{|c|}{ Predicted probabilities for a welder } & \multicolumn{3}{|c|}{ Predicted probabilities for a fitter } \\
\hline & Stage 0 & Stage 1 & Stage $2 / 3$ & Stage 0 & Stage 1 & Stage 2/3 \\
\hline 10 & 0.85 & 0.10 & 0.05 & 0.96 & 0.03 & 0.01 \\
\hline 20 & 0.68 & 0.19 & 0.13 & 0.89 & 0.07 & 0.04 \\
\hline 30 & 0.44 & 0.27 & 0.29 & 0.76 & 0.14 & 0.10 \\
\hline 40 & 0.23 & 0.25 & 0.52 & 0.53 & 0.25 & 0.22 \\
\hline
\end{tabular}


the clinical examination, and the overall objective test results, using the scoring system outlined in table 2 . These test results showed the severity of the reduced sensory perception, reduced tactile discrimination, and manipulative dexterity.

However, the scoring system outlined in table 2 is based on a crude addition of scores derived from the objective tests. It takes no account of the relation between the results of the various tests and assigns essentially the same weight to each test. The logistic regression analysis, which uses the actual values recorded in the objective tests rather than a crude score based on arbitrary categorisation, shows that the objective tests most strongly associated with the neurological stage are thermal neutral zones and log vibrotactile threshold $31.5 \mathrm{~Hz}$. The remaining objective tests, while useful individually, are not useful in predicting stage in addition to these two. The logistic regression should indicate how the scoring system used by the examiner might be modified in future studies. Further work with a larger number of subjects would help to explore the relation between the objective test results and neurological staging.

Unfortunately there was no association between the cold provocation test results and the vascular staging. This is a major problem. While waiting for an improved practical vascular test we suggest that some guidance can be gained from the neurological test results. We found that the aesthesiometry, thermal neutral zones, and vibrotactile threshold test results all associated with the vascular staging although this association was less strong than that with the neurological staging. The association of the $125 \mathrm{~Hz}$ vibrotactile threshold with vascular stage was stronger than that for the $31.5 \mathrm{~Hz}$ vibrotactile threshold. This association of the vibrotactile threshold at $125 \mathrm{~Hz}$ with the vascular staging has previously been reported. ${ }^{25}$

The $\mathrm{HSE}^{6}$ states that "It is not advisable for workers to continue exposure (to vibration) if this is likely to result in the disease progressing to Stockholm stage 3 either vascular or neurological".

With the publication of this advice to workers with HAVS, accurate staging has become of great importance. It can be devastating for a worker, in the middle of his working life, to be told that he should stop exposure to vibration. Giving such advice without actual evidence of damage to either the neurological or vascular components is, in our opinion, unwise.

Individual stages of the Stockholm workshop scales are not clear cut entities and cannot be used as gold standards. For this reason the terminology specificity and sensitivity of the performance of the individual tests has not been used. Neurological stage 2 covers a wide range of severity. A worker at an early neurological stage 2 has transient relatively minor symptoms and lower neurological objective test scores whereas one at a late neurological stage 2 has severe persistent symptoms and higher objective test scores. It is this worker who is in danger of progressing to neurological stage 3 .

We think that, with a detailed history and the neurological objective test results, advice can be given, with greater confidence, on the risks that the worker might progress to stage 3 of the HAVS.

In this study, years of exposure to use of vibratory tools and total hours of exposure were strongly associated with both the neurological and vascular staging. However, it was years of tool use rather than estimated total hours of exposure which showed the most significant association. It may be that our estimates of exposure to vibration for the various trades were not accurate. These results suggest that, in the absence of an accurate estimate of total hours of exposure, the number of years of exposure can be considered as a substitute. The use of these tools has changed over the past 20 years with increasing flexibility between trades. Also the requirements for grinding and chipping varied from contract to contract. Knowledge of a worker's exposure history allows the probability of each neurological and vascular stage to be estimated.

Many previous studies have given prevalence rates for various industries. However, most of these studies have been based on the answers to questionnaires. In this study the overall prevalence of neurological stages $\geqslant 1$ was $62 \%$ and for vascular stages $\geqslant 1$ it was $33 \%$. Letz et $a l^{9}$ found a prevalence of neurological symptoms of $50 \%$ and vascular symptoms of $33 \%$ in part time exposed workers. However, the mean years of exposure in our study was 23.3 years compared with the mean exposure time of 9.1 years found by Letz et al. ${ }^{9}$ It is in keeping with several other studies that the prevalence of neurological HAVS in this study was greater than the prevalence of vascular HAVS. ${ }^{26}{ }^{27}$

The mean latent period for the onset of neurological symptoms was 19.7 years and for vascular symptoms 19.1 years. There were significant differences between the trades. The latent periods for dressers and welders were shorter than the latent periods for fitters and platers. Dressers were known to have longer hours of exposure. Welders were the only trade to use pneumatic chipping hammers as well as grinders. Chipping hammers have higher acceleration and cause more damage than grinders for the same exposure time.

We are indebted to the directors of the company for the provision of the facilities and equipment. We are also indebted to the employees for their full cooperation and to the nurses who persevered to complete the examinations.

1 Brereton P. Progress in persuading British industry that effective management of exposure to hand-arm vibration results in good health and good business. Proceedings of the 8th International Conference on Hand-Arm Vibration, Umea. Solna, Sweden: Arbets Miljo Institet, 1998:83-4.

2 Brammer AJ, Taylor W, Lundborg G. Neurological stages of the hand-arm vibration syndrome. Scand $\mathcal{F}$ Work Environ Health 1987;13:279-83.

3 Gemne G, Pyykko I, Taylor W, et al. The Stockholm workshop scale for the classification of cold-induced Raynaud's phenomenon in the hand arm vibration syndrome: revision phenomenon in the hand ar. Scation syndrome: revision of the Taylor-Pelm

4 Department of Health and Human Services. Criteria Document for a recommended standard; occupational exposure to hand-arm vibration. Cincinnati: US Department of Health and Human Services, National Institute for Occupational Safety and Health, 1989;89:106. 
5 Working Party of the Faculty of Occupational Medicine of the Royal College of Physicians. Report: part 1 handtransmitted vibration. London. RCP, 1993:11, 27.

6 Health and Safety Execu HSE, 1994;88:27, 31

7 Industrial Injuries Advisory Council. Report: hand arm vibration syndrome (vascular and neurological component involving fingers and thumb). London: IIAC, May 1995 appendix 2 .

8 Taylor W, Pelmear PL. Vibration white finger in industry. London: Academic Press, 1975.

9 Letz R, Cherniack M, Gerr F, et al. A cross sectional epidemiological survey of shipyard workers exposed to handarm vibration. Br f Ind Med 1992;49:53-62.

10 Griffin MJ. Measurement, evaluation, and assessment of occupational exposures to hand-transmitted vibration. Occup Environ Med 1997;54:73-89.

11 Moberg E. Methods for examining sensibility in the hand In Flynn JE, ed. Hand surgery. Baltimore: Williams and Wilkins 1966:435-49.

12 Renfrew S. Aesthesiometers. Lancet 1960;i:1011.

13 Renfrew S. Fingertip sensation. A routine neurological test. Renfrew S. Fingertip

14 Carlson WS, Samueloff S, Taylor W, et al. Instrumentation for measurement of sensory loss in the fingertips $\mathcal{F}$ Occup Med 1979;21:260-4.

15 Hayward R, Griffin MJ. Measures of vibrotactile sensitivity in persons exposed to hand transmitted vibration. Scand $\mathcal{F}$ Work Environ Health 1986;12:423-27.

16 Harada N, Griffin MJ. Factors influencing vibration thresholds used to assess occupational exposures to hand transmitted vibration. Br F Ind Med 1991;48:185-92.
17 Ekenvall L, Nilsson BY, Gustavson P. Temperature and vibration thresholds in vibration syndrome. Br $\mathcal{F}$ Ind $M e d$ vibration thresh

18 Swerup C, Nilsson BY. Dependence of thermal thresholds in man on the rate of temperature change. Acta Physiol Scand 1987;131:623-4.

19 Welsh CL. Digital rewarming time in the assessment of vibration induced white finger. Scand $\mathcal{F}$ Work Environ Health 1986;12:249-50.

20 McGeoch KL, Gilmour WH, Taylor W. Neurological objective tests in the assessment of hand-arm vibration syndrome. Occup Environ Med 1994;51:57-61.

21 Lawson IJ, Review of objective tests for hand-arm vibration syndrome. Occup Med 1997;1:15-20.

22 Hosmer DW, Lemeshow S. Applied logistic regression. New York: Wiley, 1989.

23 Olsen N, Diagnostic tests in Raynaud's phenomena in workers exposed to vibration: a comparative study. $B r \mathcal{F}$ Ind Med 1988;45:426-30.

24 Pelmear PL, Wong L, Dembek B. Laboratory tests for the evaluation of hand-arm vibration syndrome. Proceedings of the evaluation of hand-arm vibration syndrome. Proceedings of the Eth International Conference on Hand-Arm Vibration, Bonn.

25 Coutu-Wakulczyk G, Brammer AJ, Piercy JE. Association Coutu-Wakulczyk G, Brammer AJ, Piercy JE. Association
between quantitative measure of tactile acuity and hand symptoms reported by operators of power tools. F Hand Surg $(\mathrm{Am})$ 1997;22:873-81.

26 Bovenzi M. Prevalence of vibration-induced white finger and assessment of vibration exposure among travertine workers in Italy. Int Arch Occup Environ Health 1988;61:25-34.

27 Virokannas H, Anttonen H, Nayha S, et al. Fournal of Low Frequency Noise and Vibration 1991;11:67-74.

\section{Rejected manuscripts}

From February 1994, authors whose submitted articles are rejected will be advised of the decision and one copy of the article, together with any reviewer's comments, will be returned to them. The fournal will destroy remaining copies of the article but correspondence and reviewers' comments will be kept. 